\title{
Antimicrobial susceptibility and molecular characterization of macrolide resistance of Mycoplasma bovis isolates from multiple provinces in China
}

\author{
Ling-Cong KONG ${ }^{1)}$, Duo GAO ${ }^{1)}$, Bo-Yan JIA ${ }^{1)}$, Zi WANG ${ }^{1}$, Yun-Hang GAO ${ }^{1)}$, Zhi-Hua PEI ${ }^{1)}$, Shu-Ming LIU ${ }^{1}$, \\ Jiu-Qing $\mathrm{XIN}^{2)}$ and Hong-Xia MA ${ }^{1) *}$ \\ ${ }^{1)}$ College of Animal Science and Technology, Jilin Agricultural University, Xincheng Street No.\#2888, Changchun 130118, P.R. China \\ ${ }^{2)}$ National Contagious Bovine Pleuropneumonia Reference Laboratory, Division of Bacterial Diseases, State Key Laboratory of \\ Veterinary Biotechnology, Harbin Veterinary Research Institute, CAAS, Harbin 150000, P.R. China
}

(Received 22 May 2015/Accepted 21 August 2015/Published online in J-STAGE 7 September 2015)

\begin{abstract}
Mycoplasma bovis has spread widely throughout the world via animal movement and has become an important pathogen of bovine respiratory disease. However, the minimum inhibitory concentrations of antimicrobials for Mycoplasma bovis have not been studied in China. The objective of this study was to determine the prevalence and antibiotic resistance of Mycoplasma bovis isolated from young cattle with respiratory infection in China. Mycoplasma bovis was detected in 32/45 bovine respiratory infection outbreaks at beef farms in 8 provinces in China. The isolates were susceptible or had medium sensitivity to ciprofloxacin, enrofloxacin and doxycycline, but were frequently resistant to macrolides (13/32, 41\%). An A2058G (Escherichia coli Numbering) mutation located in the rrnA operon in domain V of $23 \mathrm{~S}$ rRNA was observed in strains that were resistant to macrolides. This single mutations at the rrnA operon in domain $\mathrm{V}$ of $23 \mathrm{~S}$ rRNA may play an important role in the resistance of Mycoplasma bovis strains to macrolides.

KEY WORDS: antimicrobial susceptibility, bovine respiratory infection, macrolides, mycoplasma bovis, target mutation
\end{abstract}

doi: 10.1292/jvms.15-0304; J. Vet. Med. Sci. 78(2): 293-296, 2016

Mycoplasma bovis (M. bovis) was first isolated from a severe case of mastitis in cattle in the United States in 1961 [7]. Subsequently, the results of some studies have suggested that $M$. bovis can cause respiratory infection, arthritis and tenosynovitis in feedlot cattle [2]. In recent years, M. bovis has spread widely to all parts of the world via animal movement and has become an important pathogen of bovine respiratory disease (BRD) in China and other countries [5]. The BRD caused by $M$. bovis is mainly treated with antibiotics, including veterinary macrolide antibiotics and fluoroquinolones in China, but treatment of BRD with macrolides often fails, leading to important economical losses in China.

Macrolide resistance has been described for pathogens of BRD, including M. bovis, Pasteurella multocida and Mannheimia haemolytica, in different countries. However, we found that the macrolide resistance of these pathogens is quite different in different countries. The genes $\operatorname{msr}(\mathrm{E})$ $m p h(\mathrm{E})$ and erm(42) have been shown to confer resistance to macrolides in Pasteurella multocida and Mannheimia haemolytica in Germany [11]. However, high-level macrolide resistance of Pasteurella multocida and Mannheimia haemolytica isolated in Europe can be due to 23S rRNA mutations [12]. One study of M. bovis isolated in Israel found that a combination of mutations in two domains of $23 \mathrm{~S}$ rRNA is

*Correspondence to: Ma, H.-X., College of Animal Science and Technology, Jilin Agricultural University, Xincheng Street No.\#2888, Changchun 130118, P.R. China.

e-mail: hongxia0731001@163.com

(C)2016 The Japanese Society of Veterinary Science

This is an open-access article distributed under the terms of the Creative Commons Attribution Non-Commercial No Derivatives (by-nc-nd) License $<$ http://creativecommons.org/licenses/by-nc-nd/3.0/>. necessary to achieve higher minimum inhibitory concentrations of macrolides (MICs, $\geq 128 \mu \mathrm{g} / \mathrm{m} l$ ) [8]. However, little research on this topic has been conducted in China. Therefore, systematic monitoring of antibiotic susceptibility and determination of the macrolide resistance mechanism of $M$. bovis strains in China are important.

A total of $32 \mathrm{M}$. bovis strains originating from 32 feedlot cattle herds located in 8 provinces in China (Jilin, Heilongjiang, Neimenggu, Liaoning, Shandong, Hebei, Henan and Jiangsu) were tested in this study. Samples from lungs and nasal swabs were collected from distinct outbreaks between 2011 and 2013. All samples were incubated on pleuropneumonia-like organism (PPLO) agar plates. Suspected colonies with typical "fried egg" morphology were selected from each sample and identified using biochemical methods and PCR assay, as described previously [13]. The number of color changing units (CCU) was calculated, and antimicrobial susceptibility testing was performed by the microplate dilution method $[4,10]$. Two-fold dilutions of antibiotics from 0.03 to $256 \mu \mathrm{g} / \mathrm{m} l$ were tested. Because there are no CLSI-approved MIC cut-off values for veterinary Mycoplasma species, it is difficult to interpret the impact of antimicrobial activity in vitro. CLSI-approved interpretative criteria for other respiratory bovine pathogens are frequently used to understand the implication of $M$. bovis sensitivity testing in vitro [6, 14]. The cut-off values for enrofloxacin and ciprofloxacin (susceptible, $\leq 0.25 \mu \mathrm{g} / \mathrm{m} l$; resistant, $\geq 2 \mu \mathrm{g} / \mathrm{m} l$ ), doxycycline (susceptible, $\leq 4 \mu \mathrm{g} / \mathrm{m} l$; resistant, $\geq 16 \mu \mathrm{g} / \mathrm{ml}$ ), clindamycin (susceptible, $\leq 0.5 \mu \mathrm{g} / \mathrm{ml}$; resistant, $\geq 4 \mu \mathrm{g} / \mathrm{m} l$ ), tulathromycin (susceptible, $\leq 16 \mu \mathrm{g} / \mathrm{ml}$; resistant, $\geq 64 \mu \mathrm{g} / \mathrm{m} l$ ) and florfenicol (susceptible, $\leq 2 \mu \mathrm{g} / \mathrm{m} l$; resistant, $\geq 8 \mu \mathrm{g} / \mathrm{m} l$ ) were defined, and the cut-off values for macrolides (susceptible, $\leq 16 \mu \mathrm{g}$ / $\mathrm{ml}$; resistant, $\geq 64 \mu \mathrm{g} / \mathrm{m} l$ ) were defined by dichotomizing the 
Table 1. Primers and PCR amplification protocols used in this study

\begin{tabular}{cclcc}
\hline Amplitication target & Primer & \multicolumn{1}{c}{ Primers sequence $\left(5^{\prime}-3^{\prime}\right)$} & $\begin{array}{c}\text { Product } \\
(\mathrm{bp})\end{array}$ & $\begin{array}{c}\text { Annealing Temperature } \\
\left({ }^{\circ} \mathrm{C}\right)\end{array}$ \\
\hline$r r n A$ & $r r n A-\mathrm{F}$ & GGATATCTAACGCCGTGTCT & 5,041 & 50 \\
& $r r n A-\mathrm{R}$ & GTACTGGTCAGCTCAACAC & & \\
rrnB & $r r n B-\mathrm{F}$ & GCATGCAAGGTTAAGCAG & 2,848 & 50 \\
& $r r n B-\mathrm{R}$ & CTAATTCCAAGTGCCACTAGCG & & \multirow{2}{*}{49} \\
L4 & L4-F & TTTAGAAAAAAGAAATGAAGACAA & 603 & \\
& L4-R & CTACTCATATTGGCGATCTAGTT & & 49 \\
L22 & L22-F & ATGAGTACTCAACAAGCTAAAGCA & 329 & 49 \\
& L22-R & AATGCTATTGATAAATTAGATGTTC & 329 & \\
\hline
\end{tabular}

latest CLSI criteria for veterinary pathogenic bacteria BRD [3]. The reference strains, Escherichia coli ATCC 25922 and M. bovis type strain PG45 (ATCC 25523), were used for a quality control. To identify rRNA mutations of $M$. bovis that confer resistance to macrolides, the two alleles that contain domain II and domain V were detected. PCR was performed according to a previous study [8]. The primers and program are shown in Table 1. PCR was performed in a $25 \mu l$ reaction volume containing $2.5 \mu l 10 \times$ PCR buffer, $0.5 \mathrm{mmol}$ $\mathrm{L}^{-1} \mathrm{dNTP}, 0.5 \mu \mathrm{mol} \mathrm{L}-1$ of each primer, 15.6 $\mu$ l PCR water and 1 U LA-Taq polymerase (Takara, Otsu, Japan). The sequences were compared with the sequence of PG45, and sequences editing, consensus and alignment construction were performed by DNASTAR and ClustalW. Numbering of nucleotide and amino acid positions is based on the 23 rRNA gene or L4/L22 proteins of Escherichia coli, respectively.

Then, the MIC of erythromycin was determined in the presence of the potent efflux inhibitors, carbonyl cyanide mchlorophenyl hydrazones (CCCPs) and verapamil, at appropriate concentrations using the broth microdilution method [17]. Some previous studies have found that MICs change in the presence or absence of inhibitors due to changes in the level of activity of efflux pumps. However, a two-fold reduction is not sufficient to rule out false positives. Thus, a four-fold or greater reduction in strain MICs in the presence of inhibitors is considered to be due to the activity of efflux pumps $[9,18]$. Each experiment was repeated three times.

The MIC values of the 10 antimicrobial agents obtained from the examinations of the China $M$. bovis isolates are shown in Table 2, and the MIC values for PG45 were as follows: erythromycin $(2 \mu \mathrm{g} / \mathrm{m} l)$, azithromycin $(2 \mu \mathrm{g} / \mathrm{m} l)$, kitasamycin $(2 \mu \mathrm{g} / \mathrm{m} l)$, tylosin $(0.125 \mu \mathrm{g} / \mathrm{m} l)$, clindamycin $(0.125 \mu \mathrm{g} / \mathrm{m} l)$, lincomycin $(0.25 \mu \mathrm{g} / \mathrm{m} l)$, doxycycline $(0.03$ $\mu \mathrm{g} / \mathrm{m} l)$, ciprofloxacin $(0.125 \mu \mathrm{g} / \mathrm{m} l)$, enrofloxacin $(0.125$ $\mu \mathrm{g} / \mathrm{m} l)$ and florfenicol $(2 \mu \mathrm{g} / \mathrm{ml})$. Fluoroquinolones were found to be the most active compounds in vitro (MIC $\leq 1$ $\mu \mathrm{g} / \mathrm{m} l)$. For one isolate, the MIC for florfenicol was high $(\mathrm{MIC}=8 \mu \mathrm{g} / \mathrm{m} l)$, while the rest of the strains were inhibited by florfenicol at lower concentrations (MIC $\leq 4 \mu \mathrm{g}$ / $\mathrm{m} l$ ). Thirteen $(41 \%)$ isolates were resistant to erythromycin, tylosin, azithromycin and kitasamycin, with MICs $\geq 64 \mu \mathrm{g} /$ $\mathrm{m} l$. The MICs of clindamycin and lincomycin were different in two distinct populations of isolates: 13 strains yielded MICs $\geq 128 \mu \mathrm{g} / \mathrm{m} l$, while the rest yielded MICs $\leq 0.125 \mu \mathrm{g} /$ $\mathrm{m} l$. These results are in accordance with previous studies in other countries, which found that the most active compounds were fluoroquinolones and florfenicol $[15,16]$. However, macrolides have been used traditionally and are losing their efficacy against $M$. bovis in many countries, which is in accordance with our results, as many $M$. bovis strains in China are already resistant to macrolides. Furthermore, the strains that were resistant to macrolides were also resistant to lincomycin and clindamycin, which has been previously observed in other Mycoplasma of animal and human origins. The mechanism of this resistance probably involves rRNA mutations $[1,10]$.

The 23S rRNA gene sequences of susceptible strains and resistance strains were analyzed (Table 3 ). The macrolideresistant strains only had one mutation type, an A2058G substitution in domain $\mathrm{V}$ in the $\operatorname{rrn} A$ operon of the $23 \mathrm{~S}$ rRNA. None of the macrolide-resistant strains contained substitutions in the $\operatorname{rrn} B$ operon. Additionally, there were no significant differences in domain II of L4 or L22 ribosomal proteins between resistant and susceptibl isolates. The A2058G substitution in domain $\mathrm{V}$ was the most prevalent substitution in our study and a previous study [8], and this single mutation may play an important role in the resistance of $M$. bovis strains to macrolides. However, other point mutations were found in previous studies in one or two domains of 23SrRNA, including G748A, C752T, A2059G and $\mathrm{A} 2059 \mathrm{C}$, which can reduce the sensitivity of M. bovis to tylosin and tilmicosin. Differences in the genotypes of different $M$. bovis strains may be due to differences in their evolutionary courses in different countries or to the development of different resistance mechanisms. Our results indicate that the values of erythromycin and azithromycin were not decreased in the presence of CCCP $(32 \mu \mathrm{g} / \mathrm{m} l$ and $64 \mu \mathrm{g} /$ $\mathrm{m} l$ for both antibiotics, respectively) or verapamil $(64 \mu \mathrm{g} / \mathrm{m} l$ and $128 \mu \mathrm{g} / \mathrm{m} l$, respectively) in highly resistant strains, and Chinese macrolide-resistant strains were negative for antibiotic efflux. Whether M. bovis strains have other resistance mechanisms should be investigated further in future studies.

This is the first report of systematic monitoring of antibiotic susceptibility of $M$. bovis in China. We believe that studies should be performed to evaluate changes in MIC values and genetic mutations to determine the prevalence of $M$. bovis strains that are resistant to different antimicrobials. 
Table 2. MICs distribution of M. bovis isolates

\begin{tabular}{|c|c|c|c|c|c|c|c|c|c|c|c|c|c|c|}
\hline \multirow{2}{*}{ Antimicrobial agents $^{\text {a) }}$} & \multicolumn{14}{|c|}{ No. of isolates with MIC $(\mu \mathrm{g} / \mathrm{m} l)^{\mathrm{b})}$} \\
\hline & $\leq 0.03$ & 0.06 & 0.125 & 0.25 & 0.5 & 1 & 2 & 4 & 8 & 16 & 32 & 64 & 128 & $\geq 256$ \\
\hline ERY & & & & & & & & & & 10 & 9 & & & 13 \\
\hline AZM & & & & 3 & 5 & 3 & 6 & 2 & & & & & & 13 \\
\hline KIT & & & & & & 1 & 9 & 8 & & & & 10 & 3 & \\
\hline $\mathrm{Tm}$ & & & & & & 4 & & 6 & & 4 & & 8 & 5 & \\
\hline TYL & & & & & & & & & & 6 & 8 & 5 & 6 & 2 \\
\hline CLI & 3 & 6 & 5 & & 5 & & & & & & & & 10 & 3 \\
\hline LIN & & 2 & 4 & 4 & 3 & 6 & & & & & & 4 & 7 & 2 \\
\hline DOX & 1 & & & 4 & 15 & 12 & & & & & & & & \\
\hline CIP & & & 2 & 10 & 16 & 4 & & & & & & & & \\
\hline ENR & 1 & & 17 & 9 & 5 & & & & & & & & & \\
\hline $\mathrm{FFC}$ & & & & & & & & 12 & 1 & & & & & \\
\hline
\end{tabular}

a) $\quad \mathrm{ERY}=$ erythromycin; $\quad \mathrm{AZM}=$ azithromycin; $\quad \mathrm{KIT}=$ kitasamycin; $\quad \mathrm{Tm}=$ tilmicosin; $\quad \mathrm{TYL}=$ tylosin; $\mathrm{CLI}=$ clindamycin; $\quad \mathrm{LIN}=$ lincomycin; $\quad \mathrm{DOX}=$ doxycycline; $\quad \mathrm{CIP}=$ ciprofloxacin; $\quad \mathrm{ENR}=$ enrofloxacin; $\mathrm{FFC}=$ florfenicol. b) Cut-off values were used according to CLSI document VET01-A4 for other respiratory bovine pathogens. Full vertical lines indicate the cut-off between intermediate and resistant strains. Dotted vertical lines indicate the cut-off between susceptible and intermediate strains.

Table 3. Molecular characterization of macrolides-resistant M. bovis field isolates

\begin{tabular}{lccccccc}
\hline Isolate types & $\begin{array}{c}\text { No. of } \\
\text { isolates }\end{array}$ & $\begin{array}{c}\text { 23S rRNA } \\
\text { Domain II } r \text { rnA }\end{array}$ & $\begin{array}{c}\text { 23S rRNA } \\
\text { Domain V rrnA }\end{array}$ & $\begin{array}{c}\text { 23S rRNA } \\
\text { Domain II rrnB }\end{array}$ & $\begin{array}{c}\text { 23S rRNA } \\
\text { Domain V rrnB }\end{array}$ & $\begin{array}{c}\text { L4 } \\
\text { ribosomal protein }\end{array}$ & $\begin{array}{c}\text { L22 } \\
\text { ribosomal protein }\end{array}$ \\
\hline resistant isolates & 13 & None & A2058G & None & None & None & None \\
susceptible isolates & 19 & None & None & None & None & None & None \\
\hline
\end{tabular}

ACKNOWLEDGMENTS. This research was funded by the National Natural Science Foundation of China (Grant No. 31272611), the National Natural Science Foundation of China (Grant No. 31140026), the World Bank Loan Project of Jilin Province (Grant No. 2011-Y05), the Science and Technology Development Plan in Jilin Province (Grant No. 20111820) and State Key Laboratory of Veterinary Biotechnology.

\section{REFERENCES}

1. Bébéar, C., Pereyre, S. and Peuchant, O. 2011. Mycoplasma pneumoniae: susceptibility and resistance to antibiotics. Future Microbiol. 6: 423-431. [Medline] [CrossRef]

2. Caswell, J. L., Bateman, K. G., Cai, H. Y. and Castillo-Alcala, F. 2010. Mycoplasma bovis in respiratory disease of feedlot cattle. Vet. Clin. N. Am-Food A. 26: 365-379.

3. Clinical and Laboratory Standards Institute 2013. Performance Standards for Antimicrobial Disk and Dilution Susceptibility Tests for Bacteria Isolated From Animals. Approved Standard, 4th ed. In: CISI document VET01-A4, CLSI, Wayne.

4. Clinical and Laboratory Standards Institute 2008. Performance standards for antimicrobial disk and dilution susceptibility tests for bacteria isolated from animals. Approved Standard, 3rd ed. In: CLSI document M31-A3, CLSI, Wayne.

5. Gautier-Bouchardon, A. V., Ferré, S., Le Grand, D., Paoli, A., Gay, E. and Poumarat, F. 2014. Overall decrease in the suscep- tibility of Mycoplasma bovis to antimicrobials over the past 30 years in France. PLoS ONE 9: e87672. [Medline] [CrossRef]

6. Gerchman, I., Levisohn, S., Mikula, I. and Lysnyansky, I. 2009. In vitro antimicrobial susceptibility of Mycoplasma bovis isolated in Israel from local and imported cattle. Vet. Microbiol. 137: 268-275. [Medline] [CrossRef]

7. Hale, H. H., Helmboldt, C. F., Plastridge, W. N. and Stula, E. F. 1962. Bovine mastitis caused by a Mycoplasma species. Cornell Vet. 52: 582-591. [Medline]

8. Lerner, U., Amram, E., Ayling, R. D., Mikula, I., Gerchman, I., Harrus, S., Teff, D., Yogev, D. and Lysnyansky, I. 2014. Acquired resistance to the 16-membered macrolides tylosin and tilmicosin by Mycoplasma bovis. Vet. Microbiol. 168: 365-371. [Medline] [CrossRef]

9. Kong, L. C., Gao, D., Gao, Y. H., Liu, S. M. and Ma, H. X. 2014. Fluoroquinolone resistance mechanism of clinical isolates and selected mutants of Pasteurella multocida from bovine respiratory disease in China. J. Vet. Med. Sci. 76: 1655-1657. [Medline] [CrossRef]

10. Lysnyansky, I., Gerchman, I., Flaminio, B. and Catania, S. 2015. Decreased Susceptibility to Macrolide-Lincosamide in Mycoplasma synoviae Is Associated with Mutations in 23S Ribosomal RNA. Microb. Drug Resist. [Medline] [CrossRef]

11. Michael, G. B., Eidam, C., Kadlec, K., Meyer, K., Sweeney, M. T., Murray, R. W., Watts, J. L. and Schwarz, S. 2012. Increased MICs of gamithromycin and tildipirosin in the presence of the genes erm(42) and $m s r(\mathrm{E})-m p h(\mathrm{E})$ for bovine Pasteurella multocida and Mannheimia haemolytica. J. Antimicrob. Chemother. 
67: 1555-1557. [Medline] [CrossRef]

12. Olsen, A. S., Warrass, R. and Douthwaite, S. 2015. Macrolide resistance conferred by rRNA mutations in field isolates of Mannheimia haemolytica and Pasteurella multocida. J. Antimicrob. Chemother. 70: 420-423. [Medline] [CrossRef]

13. Rifatbegović, M., Assunção, P., Poveda, J. B. and Pasić, S. 2007. Isolation of Mycoplasma bovis from the respiratory tract of cattle in Bosnia and Herzegovina. Vet. Rec. 160: 484-485. [Medline] [CrossRef]

14. Rosenbusch, R. F., Kinyon, J. M., Apley, M., Funk, N. D., Smith, S. and Hoffman, L. J. 2005. In vitro antimicrobial inhibition profiles of Mycoplasma bovis isolates recovered from various regions of the United States from 2002 to 2003. J. Vet. Diagn. Invest. 17: 436-441. [Medline] [CrossRef]

15. Sato, T., Okubo, T., Usui, M., Higuchi, H. and Tamura, Y. 2013. Amino acid substitutions in GyrA and ParC are associated with fluoroquinolone resistance in Mycoplasma bovis isolates from Japanese dairy calves. J. Vet. Med. Sci. 75: 1063-1065. [Med- line] [CrossRef]

16. Shin, S. B., Yoo, M. H., Jeong, J. B., Kim, Y. M., Chung, J. K., Huh, M. D., Komisar, J. L. and Jeong, H. D. 2005. Molecular cloning of the gyrA gene and characterization of its mutation in clinical isolates of quinolone-resistant Edwardsiella tarda. Dis. Aquat. Organ. 67: 259-266. [Medline] [CrossRef]

17. Soehnlen, M. K., Kunze, M. E., Karunathilake, K. E., Henwood, B. M., Kariyawasam, S., Wolfgang, D. R. and Jayarao, B. M. 2011. In vitro antimicrobial inhibition of Mycoplasma bovis isolates submitted to the Pennsylvania Animal Diagnostic Laboratory using flow cytometry and a broth microdilution method. J. Vet. Diagn. Invest. 23: 547-551. [Medline] [CrossRef]

18. Spigaglia, P., Barbanti, F., Louie, T., Barbut, F. and Mastrantonio, P. 2009. Molecular analysis of the gyrA and $g y r \mathrm{~B}$ quinolone resistance-determining regions of fluoroquinolone-resistant Clostridium difficile mutants selected in vitro. Antimicrob. Agents Chemother. 53: 2463-2468. [Medline] [CrossRef] 